\title{
RESEARCH
}

Open Access

\section{Different strategies in the management of thalamic space-occupying lesions}

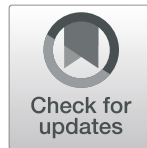

Ahmed Abdel Aziz Fayed", Osama Abdel Aziz and Mohamed Eshra

\begin{abstract}
Introduction: Thalamic space-occupying lesions (SOL) are considered challenging for microsurgical removal. Unfortunately, the pathological features of lesions occurring in the thalamic region are different with a wide variation in clinical behavior and outcome. Although microsurgery is still the gold standard in the management of these lesions through different approaches, questions remain whether surgery is feasible and safe in these patients and what are the alternatives? It is well known that stereotactic techniques may be favorable especially in cystic, small, multiple lesions and in combination with adjuvant therapy. Transventricular endoscopic approach is also an alternative technique to combine tumor biopsy and treatment of hydrocephalus.
\end{abstract}

Aim of the study: The identification of the different procedures for the management of thalamic SOL in respect to the age of the patient, the clinical condition, and the site of the lesion as well as its extent and pathology.

Patients and methods: This prospective study included 35 patients having thalamic lesions with a mean age of 27 years old who were treated with different approaches including microsurgical, stereotactic, and endoscopic approaches. The clinical outcome was assessed as the same, improved, deteriorated, or died in comparison to the initial clinical status, while the radiological control was measured as no gross residual, residual $<10 \%$ and residual $>10 \%$. Chi-square test was used to test the association between two categorical variables.

Results: Thirty-five patients were included in this study, 20 were males and 15 were females. Eight cases were children, and 27 cases were adults. The most common clinical presentation was contralateral hemiparesis. The most common pathology was pilocytic astrocytoma. Radiological studies showed that the total thalamic type was the most common topographic variant and that 10 cases had hydrocephalus treated with CSF diversion procedures. For the definitive lesion, 2 cases underwent endoscopic biopsy and cystoventriculostomy and 18 cases had stereotactic technique in the form of biopsy, aspiration, and ommaya reservoir application, while 15 cases had microsurgery through different approaches with stereotactic technique preceding surgery in 2 of them.

Conclusion: The main factors involved in choosing the appropriate approach included nature of the lesion (solid or cystic, multiplicity), suspected pathological type, and diffusion tensor imaging. Abscesses are best treated with stereotaxy, while non-neoplastic cystic lesions (other than abscesses) related to the ventricles are best treated with endoscopy. For the remaining pathologies, maximum surgical removal is the best management. Best lesion control was provided by microsurgery.

Trial registration: ISRCTN 1380 registered 6/11/2018

Keywords: Thalamic, Stereotaxy, Endoscope

* Correspondence: dr.ahmadfayed@gmail.com

Neurosurgery Department, Faculty of Medicine, Alexandria University, Alexandria, Egypt

(c) The Author(s). 2020 Open Access This article is licensed under a Creative Commons Attribution 4.0 International License, which permits use, sharing, adaptation, distribution and reproduction in any medium or format, as long as you give appropriate credit to the original author(s) and the source, provide a link to the Creative Commons licence, and indicate if changes were made. The images or other third party material in this article are included in the article's Creative Commons licence, unless indicated otherwise in a credit line to the material. If material is not included in the article's Creative Commons licence and your intended use is not permitted by statutory regulation or exceeds the permitted use, you will need to obtain permission directly from the copyright holder. To view a copy of this licence, visit http://creativecommons.org/licenses/by/4.0/. 


\section{Introduction}

The thalamus has a unique anatomical configuration. It has three free surfaces with its ventrolateral border in contact with the subthalamic nuclei and the internal capsule. Its relation to important and vital structures hinders gross total resection and makes it hazardous and questionable regarding the increased risks of associated morbidity with poor outcomes $[1,2]$.

Thalamic lesions are classified into (1) unilateral thalamic tumors, originating from one thalamus with possible extension to adjacent structures; (2) thalamopeduncular tumors, arising at the junction of the thalamus and the cerebral peduncle with symmetrical supra- and infratentorial extension; and (3) bilateral thalamic tumors, originating from both thalami as opposed to tumors with contralateral extension [3].

There is a relation between the patients' age and the pathological grade of thalamic lesions: they are usually malignant in adults with limited possibility of radical removal, while they are often benign in children and could be removed totally with better outcome [4-6]. Thalamic space-occupying lesions (SOL) include different pathological types as different grades of gliomas, lymphomas, metastasis, pyogenic abscesses, arteriovenous malformations, cavernomas, and thalamic neuroepithelial cysts [6-10].

The most common clinical presentations associated with thalamic space-occupying lesion are manifestations of increased ICP and/or motor deficits [3]. Medial or dorsal thalamic lesions protruding in the ventricular system have a greater probability of causing obstructive hydrocephalus. Presentation with sensory deficits is unusual $[3,10]$.

Recent imaging modalities including diffusion tensor imaging provide an important tool for the planning of operative approaches to thalamic lesions as well as decreasing the risk of postoperative morbidity [11-13].

The appropriate management for these lesions is still debatable with no standard treatment strategy [4, 13-15]. Different techniques have been discussed in the literature including endoscopic techniques in the form of biopsy or cerebrospinal fluid (CSF) diversion [16], stereotactic techniques in the form of biopsy or cyst aspiration [17], and microsurgery that could provide total or subtotal resection [3].

Microsurgery could be performed through (1) transcortical transventricular approaches whether parietal for pulvinar lesions and those extending laterally or frontal for those with anterior thalamic locations, (2) anterior interhemispheric transcallosal-transventricular approach in tumor extending from anterior to posterior in a longitudinal shape, (3) contralateral infratentorial supracerebellar approach used mainly for lesions arising from the pulvinar and extending in the posterior third ventricle, (4) posterior interhemispheric parasplenial approach commonly described as the preferred approach for lesions involving the medial wall of the trigone and pulvinar, and (5) transylvian transinsular approach for lateral thalamic lesions $[18,19]$.

\section{Subjects and methods}

This prospective study included 35 patients with thalamic lesions who underwent preoperative evaluation including patient demographics and clinical examination, and neuroimaging studies including magnetic resonance (MR) imaging prior to treatment and during the followup period, and in addition, most patients had undergone a preoperative head CT scan. Certain cases did MR tractography. Heterogeneity, cystic nature of the lesions, presence of calcification, contrast enhancement, and the presence of hydrocephalus were noted. Planning of the definite procedure was based on age of the patient, site of the tumor, its extent, its neuroimaging feature, expected grade of malignancy, feasibility of safe biopsy, and total resection.

The procedure applied included one or a combination of the following:

- Stereotactic biopsy using Leksell stereotactic frame

- Endoscopic third ventriculostomy using 0 lens rigid Gaab endoscope

- Endoscopic fenestration and biopsy using 0 lens rigid Gaab endoscope

- Total microsurgical excision

- Partial microsurgical excision

- Postoperative radiotherapy and chemotherapy

Postoperative evaluation includes early postoperative evaluation and after 6 months for clinical outcome and tumor control. Clinical outcome was recorded as clinical improvement (defined as partial or complete relief of symptoms), same or unchanged, deteriorated state (defined as progression of clinical symptoms), and died. Radiological control was assessed by the residual size of the lesion on postoperative images after 6 months. They were categorized as partial resection with residual (> $10 \%)$, subtotal resection $(<10 \%)$, or gross total resection with no residual tumor on postoperative imaging.

Written informed consent to participate in the study was provided by all participants.

\section{Results}

Age and sex distribution among patients (Table 1)

\section{Distribution of the lesion}

None of the cases were bilateral; 21 lesions (60\%) were located in the right thalamus while 14 lesions (40\%) were located in the left thalamus (Fig. 1). 
Table 1 Age and sex distribution among patients

\begin{tabular}{|c|c|c|c|c|c|c|}
\hline & \multicolumn{2}{|c|}{ Males } & \multicolumn{2}{|c|}{ Females } & \multicolumn{2}{|l|}{ Total } \\
\hline & $<18 y$ & $>18 y$ & $<18 y$ & $>18 y$ & Male & Female \\
\hline Number of patients & 7 & 13 & 13 & 14 & 20 & 15 \\
\hline Percentage (\%) & 20 & 37 & 37 & 40 & 57 & 43 \\
\hline
\end{tabular}

\section{Topographic variants (Fig. 2)}

- Anterior (at the level of foramen of Monro): three cases $(8.5 \%)$

- Lateral: five cases (14.3\%)

- Posterior: nine cases (25.7\%)

- Total (occupying the whole thalamus): 16 cases (45.8\%)

- Thalamopeduncular: two cases (5.7\%)

\section{Pathology}

These lesions were classified into solid, partly solidcystic, and cystic lesions. The most common pathology was pilocytic astrocytoma (35\%) followed by grades II and III gliomas (32\%), GBM (15\%), abscess (12\%), and benign cyst (6\%).

\section{Relation of the pathology with the age}

- Most common pathology below 18 years was pilocytic astrocytoma (87\%).

- Most common pathology above 18 years was highgrade glioma (39\%).

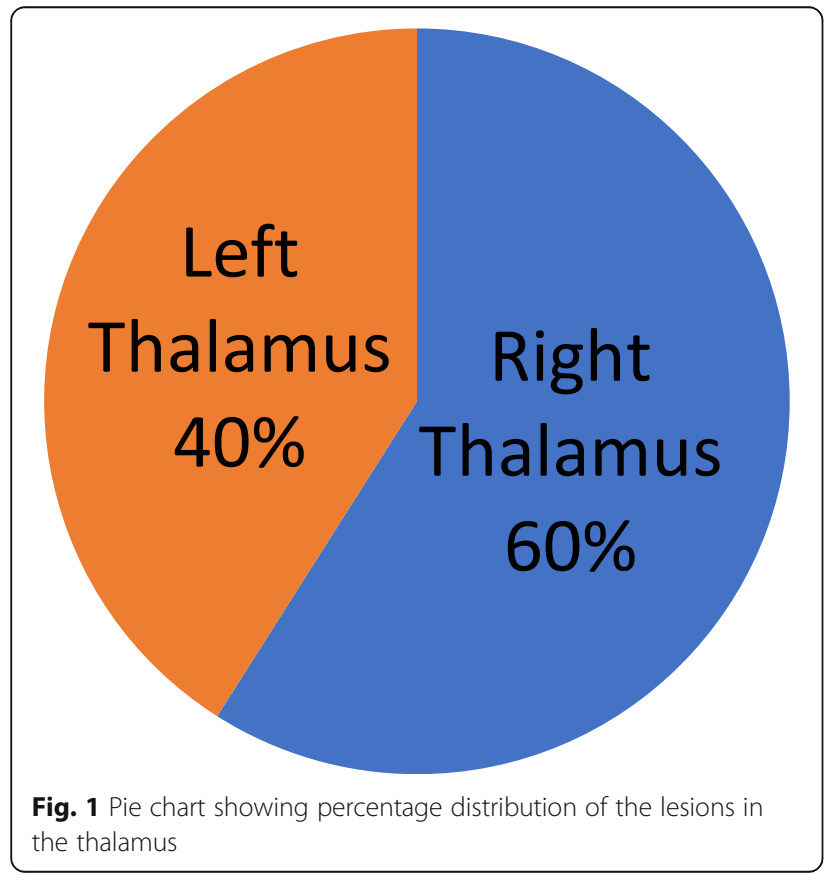

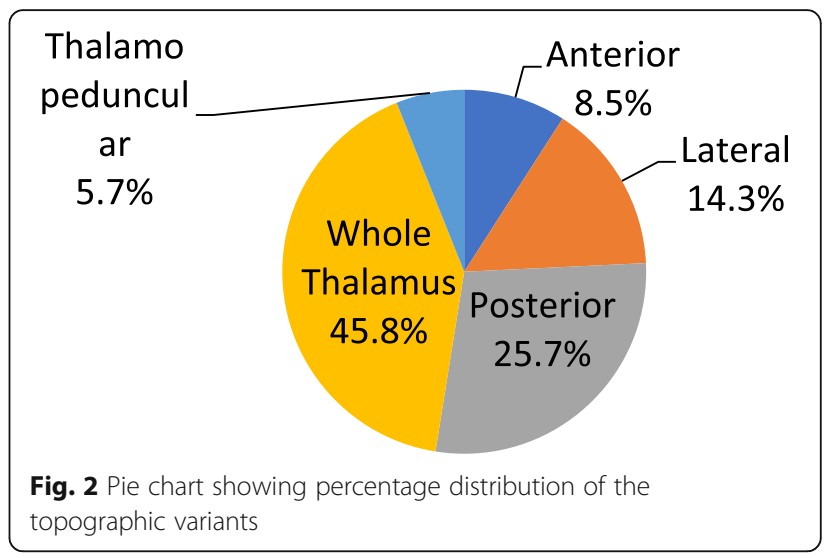

\section{Clinical presentation}

Most common clinical presentation was hemiparesis in 21 cases(60\%), followed by manifestation of increased ICP (headache, nausea, and vomiting) in 13 cases (37\%), 3 cases $(8.5 \%)$ presented with hemiparathesia, 1 case (3\%) showed signs of meningeal irritation signs, and 1 case $(3 \%)$ presented with convulsion.

\section{Imaging criteria (Table 2)}

\section{Distribution and management of hydrocephalus Hydrocephalus was found in 10 cases}

- Five total thalamus

- Four posterior thalamus

- One anterior thalamus

\section{Level of obstruction}

- Eight cases at the third ventricle

- Two cases at the Foramen of Monro (1 case anterior thalamic and the other total thalamic).

1. VP shunt

- Done in seven cases VP shunt was inserted before definitive surgery because radicality was questionable with the level of obstruction at the third ventricle

2. VP shunt and endoscopic septostomy

- Done in two cases with the level of obstruction at the foramen of Monro

3. Endoscopic cystoventriculostomy and third ventriculostomy 
Table 2 Imaging criteria of different pathologies

\begin{tabular}{|c|c|c|c|c|c|c|}
\hline \multirow[t]{2}{*}{ Pathology } & \multirow[t]{2}{*}{$C T$} & \multicolumn{5}{|l|}{ MRI } \\
\hline & & T1WMRI & T2WMRI & T1WMRI contrast & DWMRI & DTI \\
\hline Pilocytic astrocytoma & $\begin{array}{l}\text { Hypo: 40\% } \\
\text { Iso: 40\% } \\
\text { Hypo/hyper:20\% } \\
\text { (calcified) }\end{array}$ & Нyро: $75 \%$ & $\begin{array}{l}\text { Hypo: } 40 \% \\
\text { Hyper:40\% }\end{array}$ & Enhancing: 55\% & No restriction & $\begin{array}{l}\text { Only } 1 \text { case showed } \\
\text { compression }\end{array}$ \\
\hline Grade 2-3 glioma & Iso: $50 \%$ & Нyро: 66\% & $\begin{array}{l}\text { Hypo: } 30 \% \\
\text { Hyper: } 30 \%\end{array}$ & Enhancing: 65\% & - & $\begin{array}{l}\text { Only } 1 \text { case showed } \\
\text { infiltration }\end{array}$ \\
\hline GBM & $\begin{array}{l}\text { Iso: } 60 \% \\
\text { Hyper: } 40 \%\end{array}$ & $\begin{array}{l}\text { Hyper: } 20 \% \\
\text { Iso: } 80 \%\end{array}$ & $\begin{array}{l}\text { Hypo: } 40 \% \\
\text { Iso: } 60 \%\end{array}$ & $\begin{array}{l}\text { Strong enhancement: } \\
100 \%\end{array}$ & - & - \\
\hline Abscess & $\begin{array}{l}\text { Central deg. with } \\
\text { enhanc. capsule } \\
100 \%\end{array}$ & Нypo: 100\% & Iso: $100 \%$ & $\begin{array}{l}\text { Enhancing capsule } \\
100 \%\end{array}$ & Diffusion restriction 100\% & - \\
\hline Benign epithelial cyst & Нypo: $100 \%$ & Нypo: 100\% & Hyper: 100\% & - & - & - \\
\hline
\end{tabular}

GBM glioblastoma, Hypo hypodense in CT, hypointense in MRI, Hyper hyperdense in CT, hyperintense in MRI, Iso isodense in CT, isointense in MRI, DTI diffusion tensor imaging, DWMRI diffusion weighted MRI

- Done in a single case with the level of obstruction at the third ventricle

\section{Management of the lesion}

Endoscopic techniques (two cases)

Endoscopic biopsy and cystoventriculostomy

- In two cases

\section{Stereotactic techniques (18 cases)}

A. Stereotactic biopsy (16 cases) (Fig. 3)

B. Stereotactic aspiration (six cases).

- Nature of aspirate: four cases were abscesses (Figs. 4 and 5)

C. Stereotactic application of ommaya reservoir (three cases) (Fig. 6)

\section{Microsurgical approaches: (15 cases) (Table 3)}

1. Transcortical transventricular (Figs. 7, 8, 9, and 10)

2. Posterior interhemispheric (Fig. 11)

3. Anterior interhemispheric (Fig. 12)

\section{Complications of the procedure (postoperative complications) \\ Stereotactic cases}

- Hemorrhage in a single case

- Superficial wound infection in a single case

\section{Microsurgical cases}

- Hemiparesis in the upper limb more than in the lower limb in a single case

- Dysphasia in a single case

\section{Outcome}

Clinical outcome after 6-month follow-up

Endoscopic cases: (two cases)

- One case improved clinically (50\%) and the other one deteriorated (50\%).

\section{Stereotactic cases: (18 cases)}

- Six cases (33\%) improved clinically, 10 cases (55\%) remained the same, and 2 cases (12\%) deteriorated

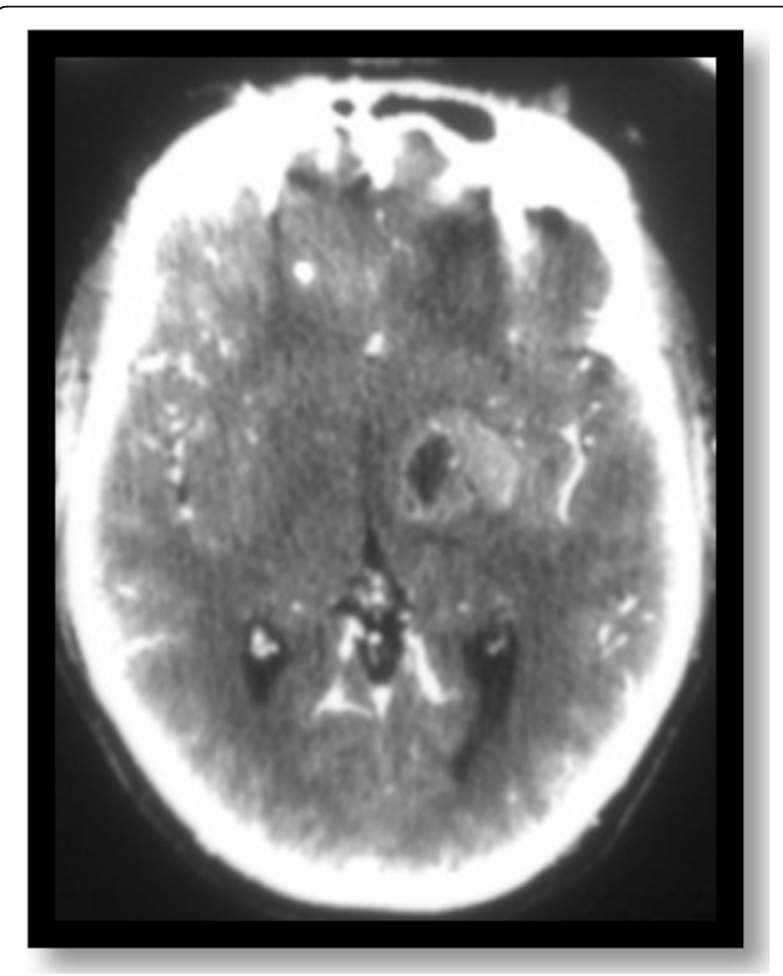

Fig. 3 Stereotactic CT for left thalamic pilocytic astrocytoma 


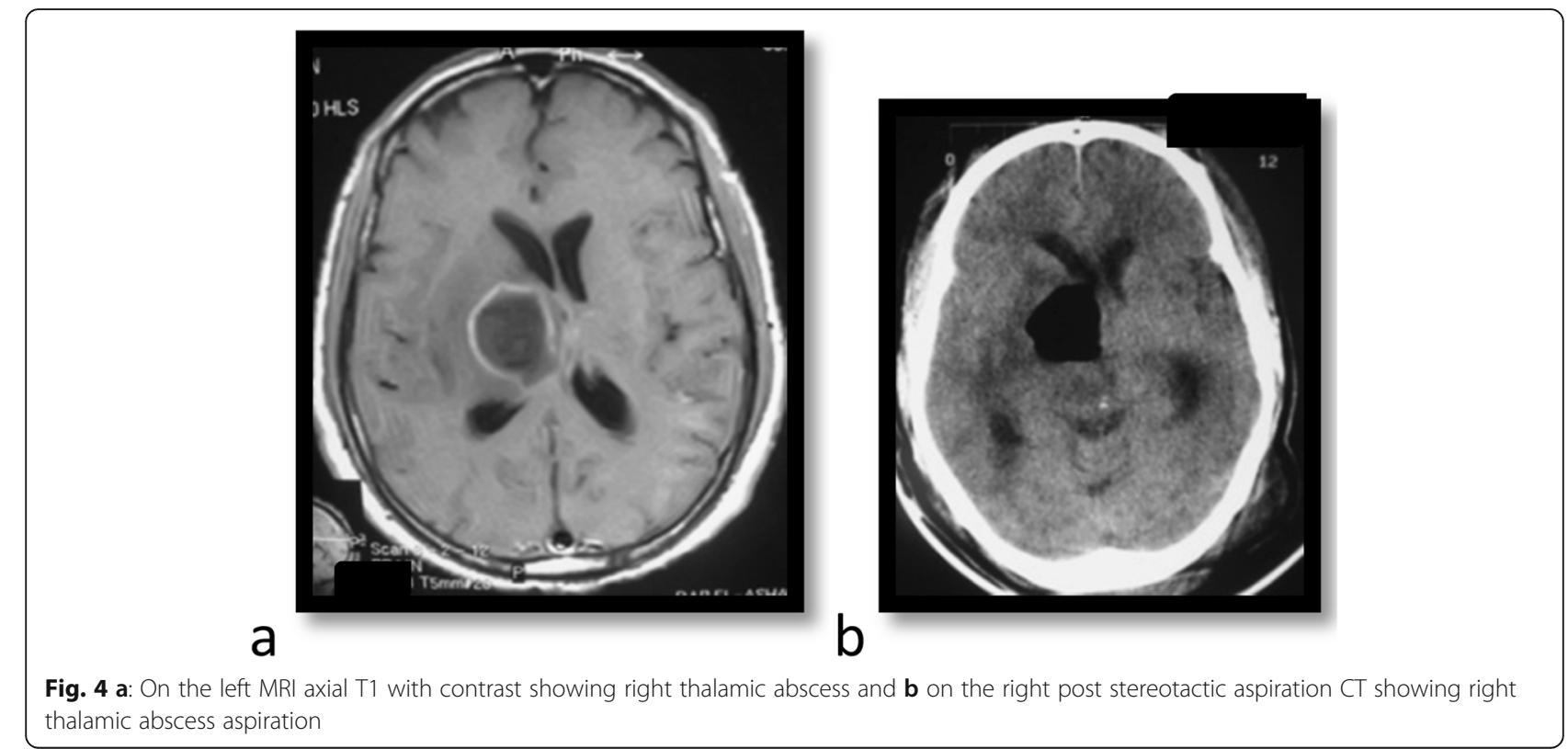

Microsurgical cases: (15 cases)

- Eight cases (53.3\%) improved clinically, three cases (20\%) remained stationary in comparison to the preoperative status, and four cases deteriorated (26.6\%), two of them were high-grade gliomas, two cases were low-grade glioma: patients deteriorated due to large residual

\section{Radiological control after 6 months}

Endoscopic cases: (two cases)

- One case showed no residual (50\%)

- One case showed residual more than $10 \%$ (50\%)
Stereotactic cases: (18 cases)

- Four cases (23\%) showed no residual or residual less than $10 \%$

- Fourteen cases (77\%) showed residual more than $10 \%$

Microsurgical cases: (15 cases)

- Ten cases $(66 \%)$ showed no residual or residual less than $10 \%$

- Five cases (33\%) showed residual more than $10 \%$

\section{Discussion}

The management of thalamic SOL should be tailored case by case. Factors involved in decision making

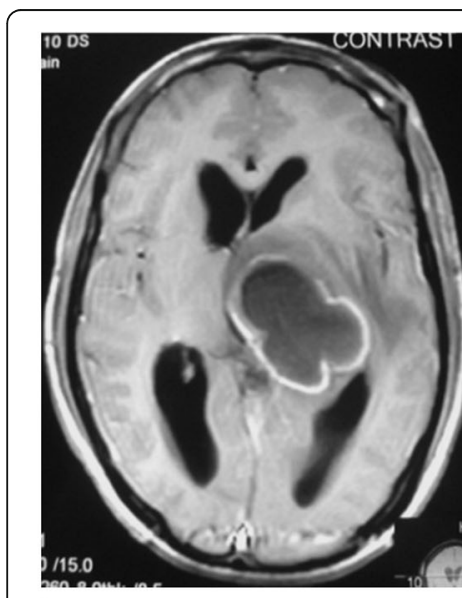

a

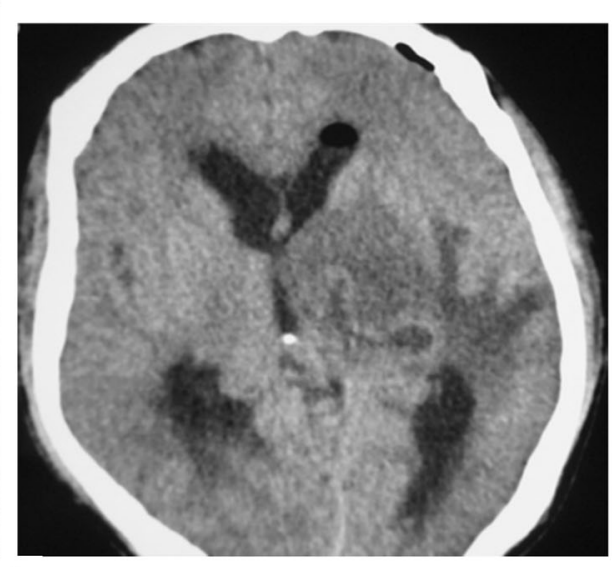

b

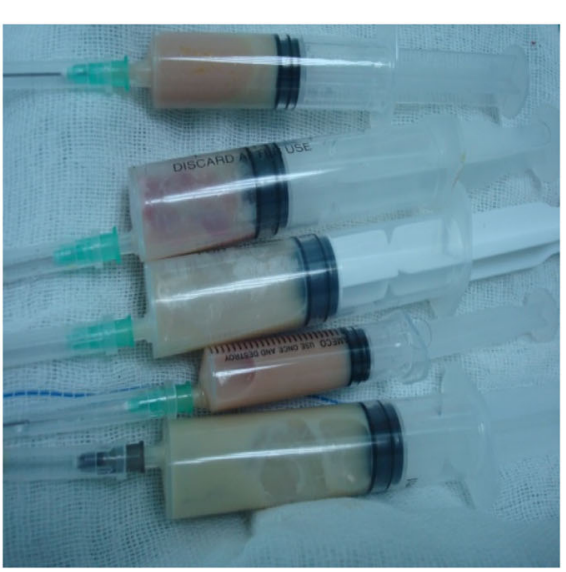

C

Fig. 5 a On the left MRI axial T1 with contrast showing left thalamic cyst and $\mathbf{b}$ on the right post stereotactic aspiration $\mathrm{CT}$ showing left thalamic cyst was aspirated, $\mathbf{c}$ below: aspirate was pus (cyst was an abscess) 


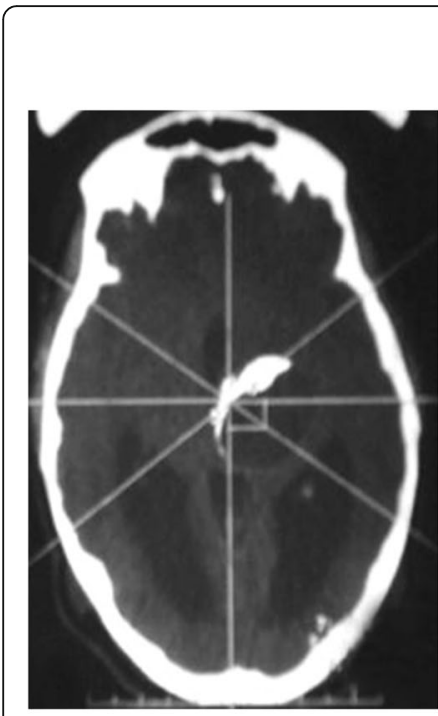

a

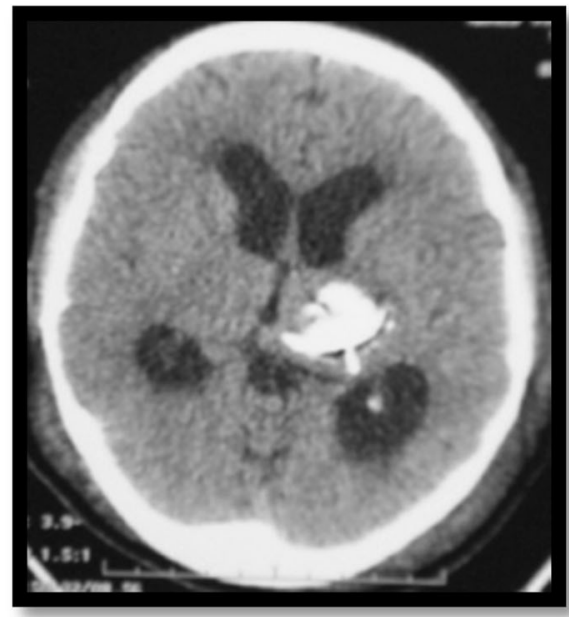

b

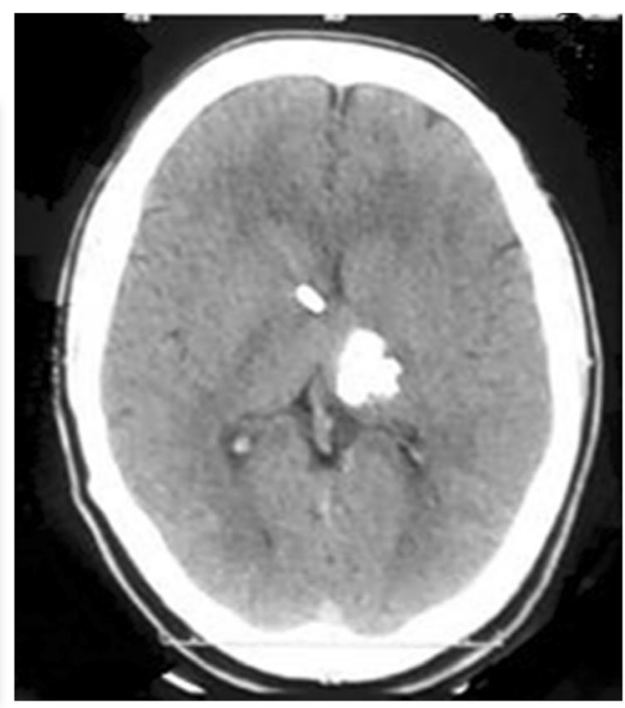

C

Fig. 6 a On the left stereotactic CT for aspiration and biopsy from left thalamic pilocytic astrocytoma, b: on the right $C T$ brain post stereotactic aspiration and application of ommaya reservoir after 2 years. $\mathbf{c}$ below presenting follow up $\mathrm{CT}$ showing stationary course with no increase in the size of the lesion

regarding the management include the pathology and morphology of the lesion whether cystic or solid. Cystic lesions in intimate relationship to the ventricular system are managed by endoscopic fenestration, as agreed by Tirakotai and Bertalanffy, as they described the role of neuroendoscopy in cystic periventricular lesions [20]. In this study, endoscopic biopsies were done in two cases: one was a thalamic tumor that was protruding in the ventricle and the other one was a thalamic cyst. Cystic lesions not in intimate relation to the ventricular system were mainly managed by stereotactic aspiration and ommaya reservoir application. In all cystic lesions, abscesses should be excluded and if proven to be abscess by MRI diffusion the best treatment is stereotactic aspiration.

Small, solid lesions are preferentially managed by stereotaxy, which was agreed by Moshel et al. who stated that the main indications of stereotactic biopsy depended on the nature of the lesion (deep seated, multiple, extensive, small, poorly defined, inflammatory, or all of these

Table 3 Different microsurgical approaches

\begin{tabular}{lll}
\hline & Site \\
\cline { 2 - 3 } & Thalamus \\
\hline Approach & No & $\%$ \\
Parietal transcortical & 9 & 60 \\
Frontal transcortical & 1 & 6 \\
Anterior interhemispheric transcallosal & 4 & 28 \\
Posterior interhemispheric & 1 & 6 \\
Total & 15 & 100 \\
\hline
\end{tabular}

characters together) [17]. Multiplicity of the lesion is an important factor in choosing a minimally invasive approach as stereotaxy or endoscopy.

Special pathological types as lymphomas and germ cell tumors give best results if treated by a minimally invasive approach as stereotaxy or endoscopy followed by adjuvant therapy rather than microsurgical resection [17].

In this study, stereotactic techniques were used in 18 cases. The main indications were (1) all cystic lesions not in intimate relation to the ventricle, (2) partly solid partly cystic lesions with calcification, (3) lesions showing corticospinal tracts infiltration in tractography, (4) small lesions, and (5) lastly patient's desire for minimally invasive technique.

Out of 18 cases that where managed by stereotaxy, only two cases developed complications, with a complication rate of $11 \%$, and the risk of intracerebral hemorrhage from stereotactic techniques was $5.5 \%$, with no perioperative mortality. This was consistent with Air, whose complication rate was $6.7 \%$ [21].

Following the 18 stereotactic cases for 6 months, 6 cases improved (33\%). The outcome depended on two important factors the pathology and the technique. The results demonstrated that the type of pathology being cystic showed statistically significant difference in relation with the improved clinical outcome in stereotactic cases as $p=0.027$.

These cases had a cystic component whether lowgrade cystic gliomas or abscesses. During the 6-month follow-up, no lesions showed recollection; however, this 


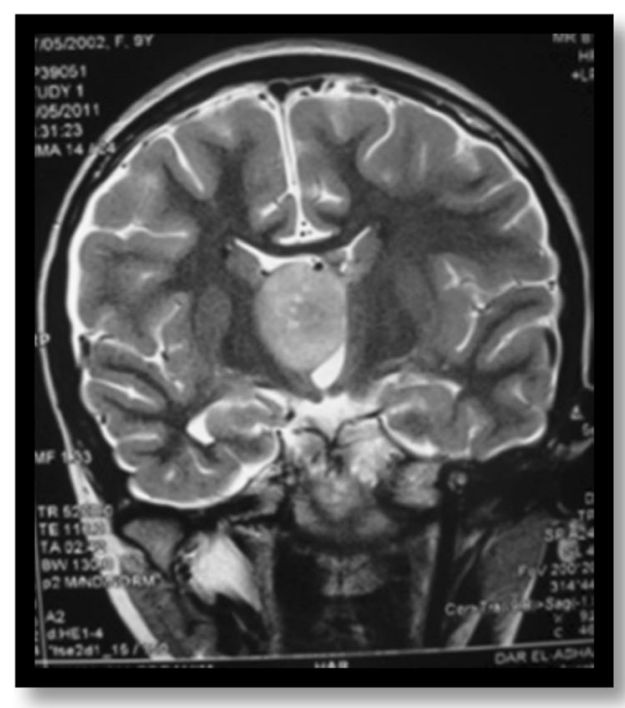

a

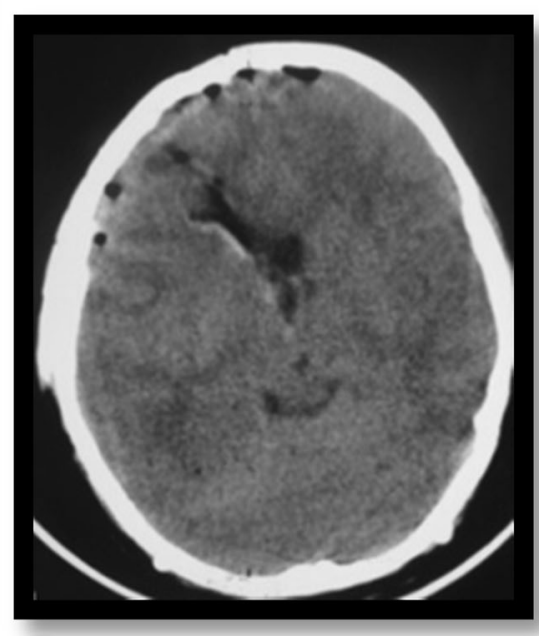

b

Fig. 7 a On the left coronal T2 MRI for anterior thalamic pilocytic astrocytoma and $\mathbf{b}$ on the right shows total removal through anterior transcortical approach (middle frontal gyrus approach)

period of clinical follow-up is too short to judge the recollection and the reappearance of manifestations. Also the technique of stereotactic aspiration is related with good clinical outcome as $p=0.01$.

However, two stereotactic cases (11\%) deteriorated and or died during the 6-month follow-up. These two lesions were high-grade gliomas, and this may explain the cause of deterioration but cannot be statistically proven.
For radiological control of the stereotactic lesions, four cases (22\%) out of 18 showed no residual or residual less than $10 \%$. Results of this study showed that the type of pathology being cystic in nature showed statistically significant difference in relation with the gross removal of the lesion (= no residual) in stereotactic cases as $p=0.046$ and that stereotactic aspiration technique showed statistical significance as regard lesion control

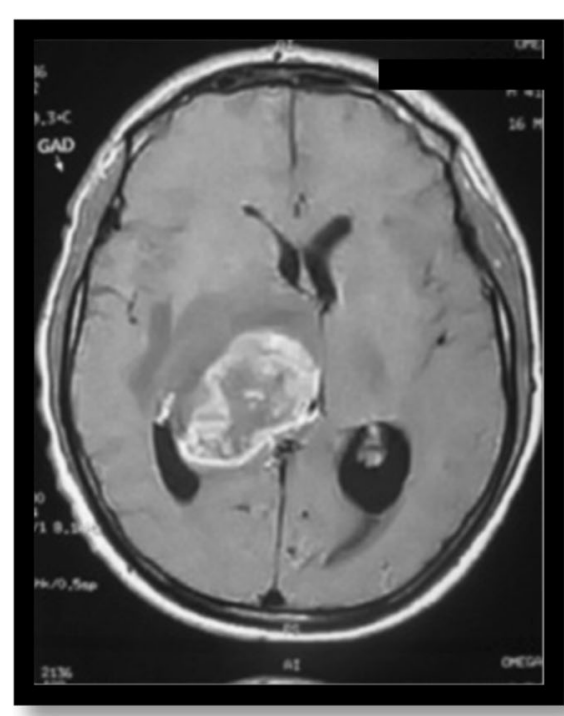

a

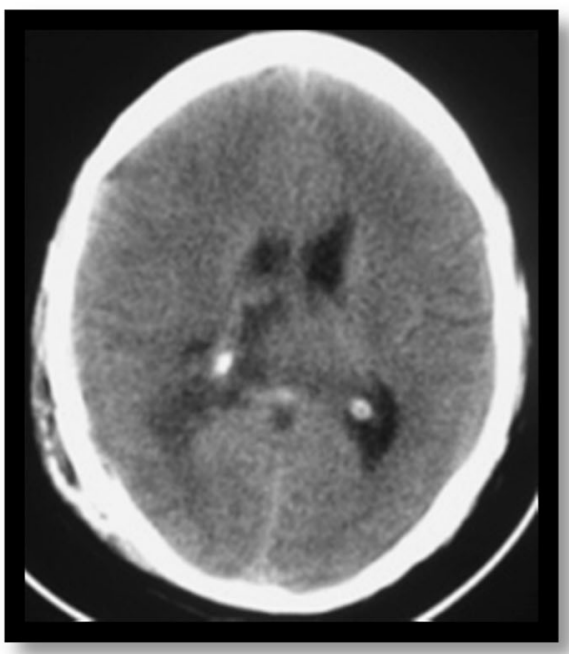

b

Fig. 8 a On the left axial T1 contrast for posterior thalamic glioma and $\mathbf{b}$ on the right follow up CT showing removal through parietal transcortical approach 


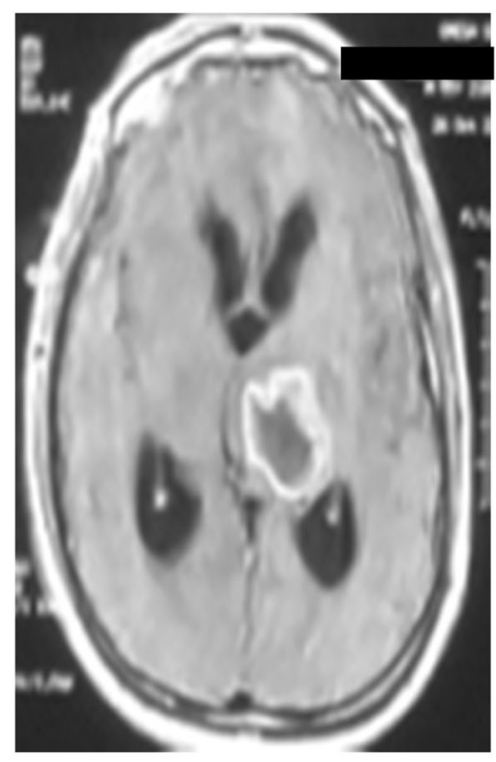

a

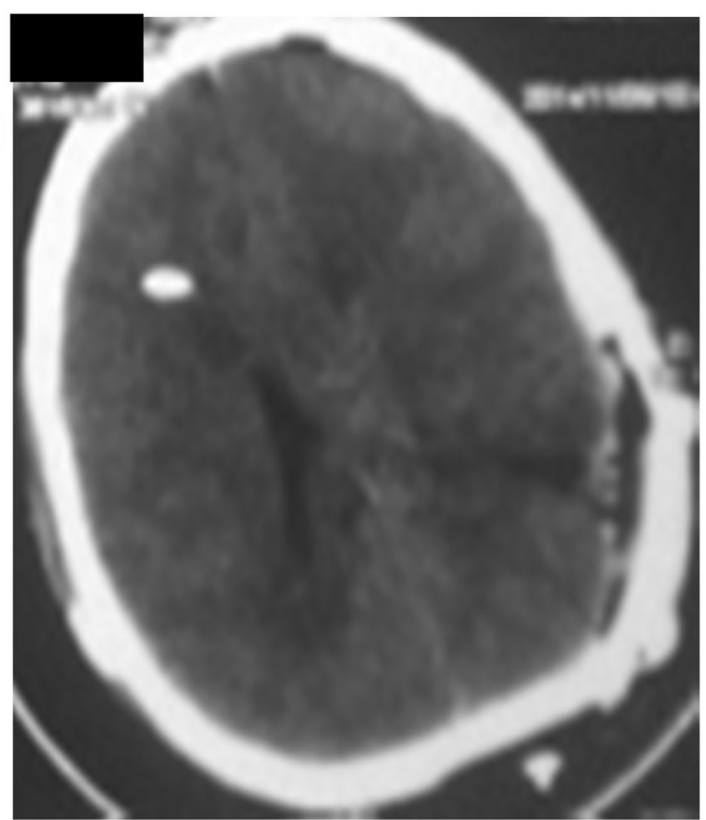

b

Fig. 9 a On the left MRI axial T1 contrast for left thalamic glioma and b on the right follow up CT showing removal through parietal transcortical approach

as $p=0.014$; this was also agreed by Air [21] who concluded that stereotactic aspiration is a useful management option for abscesses located in eloquent or inaccessible regions.

In large solid lesions, debulking by microsurgery is usually the best, as declared by Zhang et al. and Puget et al.; in their series, larger resection, whether it was in patients with a low- or high-grade lesions, was associated with better clinical outcome, proving that the extent of resection is an important determinant [3, 22]. In large solid lesions planned for microsurgery, MR tractography is usually indicated to assess the feasibility of microsurgery, the designed approach, and the expected morbidity, this was supported by Moshel et al. who showed the important role of tractography in choosing and planning the surgical approach through confirming

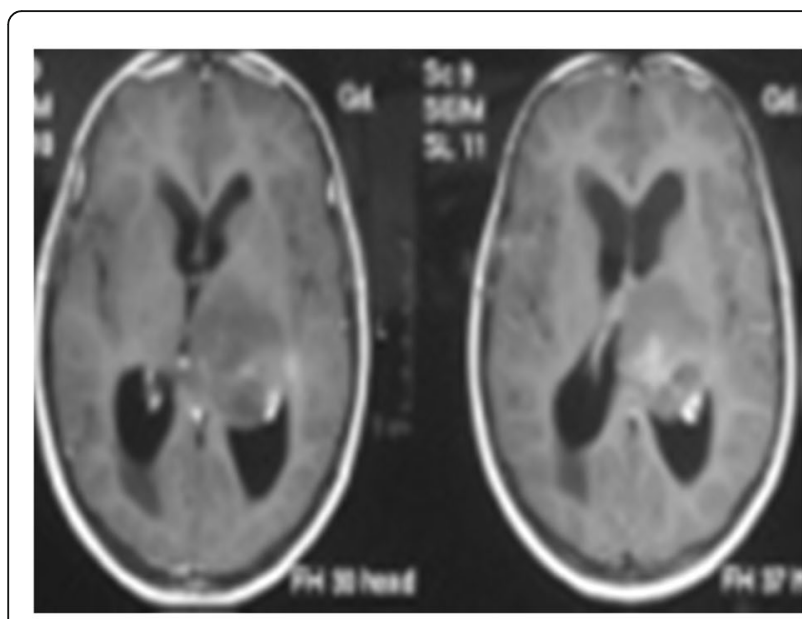

a

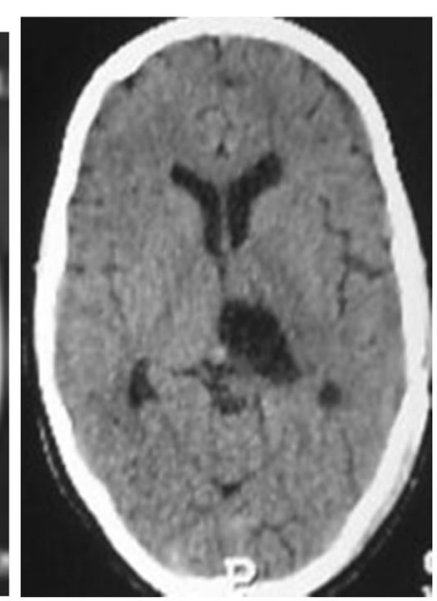

b

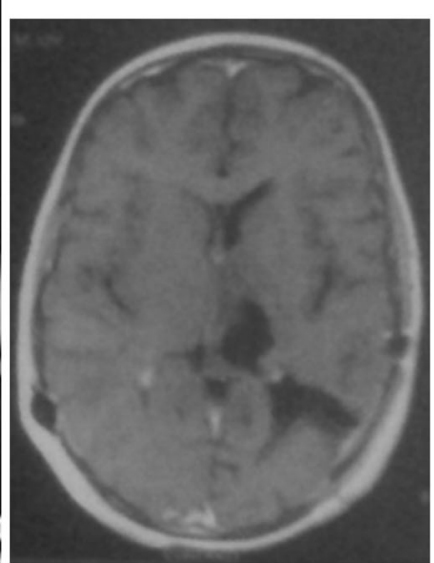

C

Fig. 10 a On the left MRI axial T1 contrast for left total thalamic pilocytic astrocytoma, $\mathbf{b}$ on the right follow up CT after 3 months showing complete removal through parietal transcortical approach, c bottom MRI axial T1 contrast done after 6 months follow up with gross total resection 


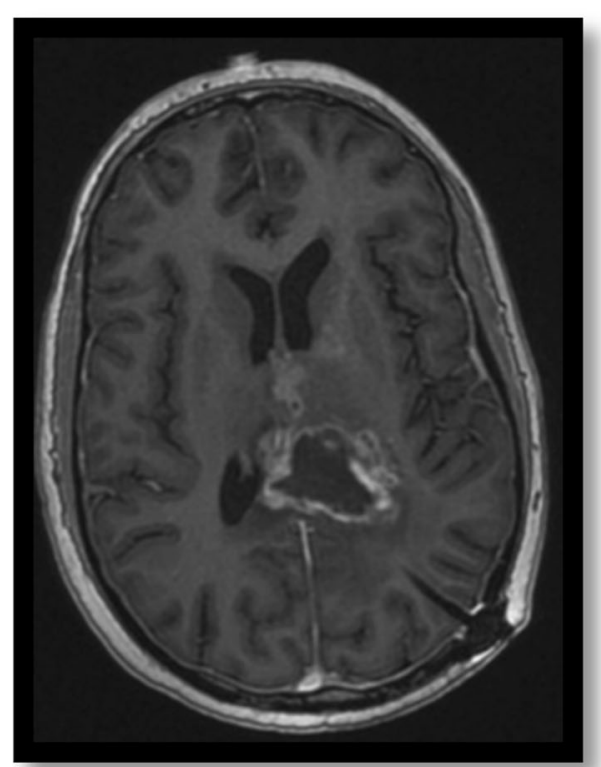

a

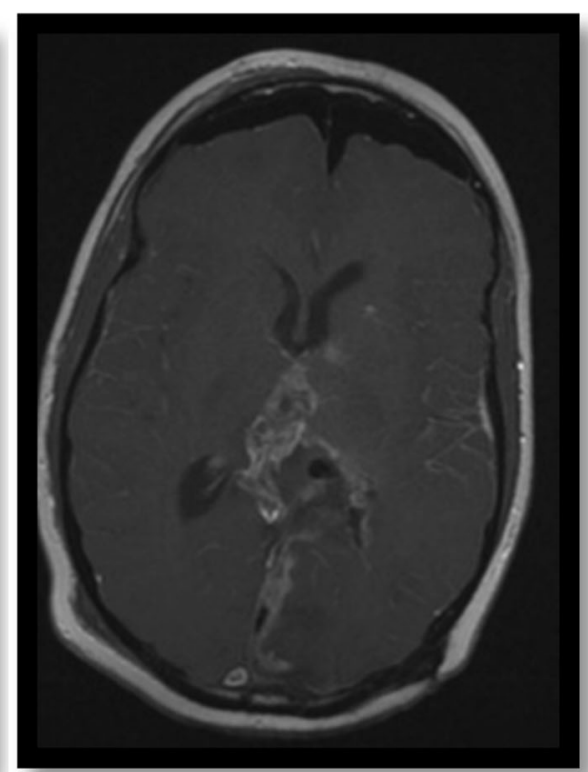

b

Fig. 11 a On the left showing axial T1 with contrast MRI for posterior thalamic glioma and $\mathbf{b}$ on the right shows subtotal removal through posterior interhemispheric approach

the relationship between white matter fiber bundles and brain tumor in preoperative decision making [12].

In the relation between the pathology of the thalamic lesions and the patients' age, eight cases were below 18 years of age, seven of them were low-grade glioma (87\%) namely pilocytic astrocytoma which was in concordance with a study by Sweet, where it showed the highest rate of low-grade glioma to be among the pediatric population [23, 24]. This emphasizes that radical removal of all lesions in patients below 18 years of age should be attempted, as they are mostly low-grade lesions and their total removal has a more favorable outcome.

As regards the relation of improved clinical outcome and microsurgery in this study, $p$ value $=0.41$ shows no statistical significance; however, this could be explained

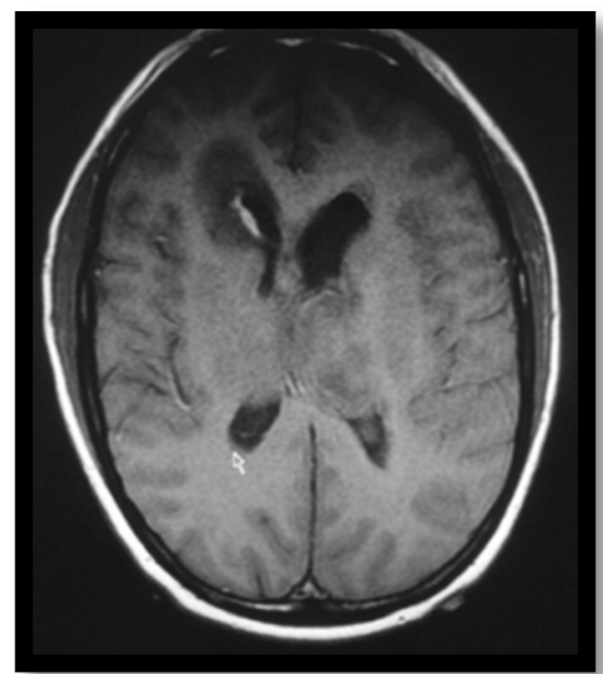

a

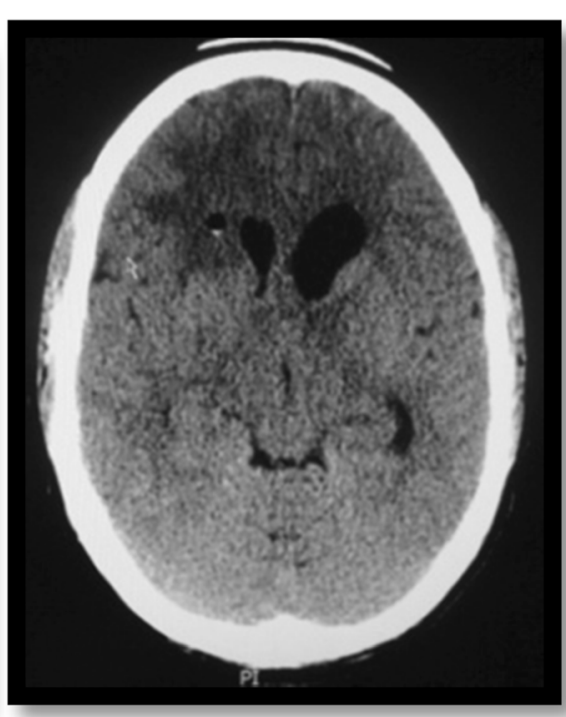

$\mathrm{b}$

Fig. 12 a On the left showing axial T1 MRI for total thalamic glioma and $\mathbf{b}$ on the right shows gross total removal through anterior interhemispheric approach 
by the short period of clinical follow-up of cases. Regarding the radiological control, there was a statistical significance between lesion control and microsurgery in this study as $p$ value $=0.03$. This was agreed by Sai Kiran et al. who concluded that radical resection results in the improvement of clinical condition as well as tumor control in majority of the patients with thalamic tumors [25].

\section{Conclusion}

The current study showed that there are different approaches for the management of thalamic lesions including endoscopic, stereotactic, and microsurgical approaches. Radiological control shows strong statistical relation with microsurgery.

\section{Abbreviations \\ CSF: Cerebrospinal fluid; MR: Magnetic resonance; SOL: Space-occupying lesions}

\section{Acknowledgments}

The authors give special thanks to the medical team and patients.

\section{Authors' contributions}

Dr. Ahmad Abdel Aziz was responsible to register the cases, follow them, involved in their surgical management as well as the corresponding author, Dr. Osama Abdel Aziz was involved in management of stereotactic cases while Dr. Mohamed Eshra was involved in the management of endoscopic cases. The author(s) read and approved the final manuscript.

\section{Funding}

No funding were available.

\section{Availability of data and materials}

The datasets used and/or analyzed during the current study are available from the corresponding author on reasonable request.

\section{Ethics approval and consent to participate}

Dear Reviewer: the date of ethical approval was 18/10/2017 with a serial number 0303739. A written informed consent to participate in the study was provided by all participants.

\section{Consent for publication}

Not applicable.

\section{Competing interests}

The authors declare that they have no competing interests.

Received: 19 December 2018 Accepted: 17 February 2020 Published online: 02 April 2020

\section{References}

1. Steiger H-J, GoÈ tz C, Schmid-Elsaesser R, Stummer W. Thalamic astrocytomas: surgical anatomy and results of a pilot series using maximum microsurgical removal. Acta Neurochir. 2000;142:1327-37.

2. Ozek MM, Ture U. Surgical approach to thalamic tumors. Childs Nerv Syst. 2002; $18: 450-6$

3. Puget S, Crimmins DW, Garnett MR, Grill J, Oliveira R, Boddaert N, et al. Thalamic tumors in children: a reappraisal. J Neurosurgery: Ped. 2007;106(5): 354-62.

4. Krouwer HG, Prados MD. Infiltrative astrocytomas of the thalamus. J Neurosurg. 1995;82(4):548-57.

5. Kocherry XG, Hegde T, Sastry KR, Mohanty A. Management of brain abscesses efficacy of stereotactic aspiration in deep-seated and eloquent-region intracranial pyogenic abscesses. Neurosurg Focus. 2008; 24(6):13.
6. Martinez-Lage JF, Perez-Espejo MA, Esteban JA, Poza M. Thalamic tumors: clinical presentation. Childs Nerv Syst. 2002;18:405-11.

7. Albright AL. Feasibility and advisability of resections of thalamic tumors in pediatric patients. J Neurosurg 2004:100 Suppl Ped(5):468-472.

8. Di Rocco C, lannelli A. Bilateral thalamic tumors in children. Childs Nerv Syst. 2002:18:440-4.

9. Duckworth E, Gross B, Batjer HH. Thalamic and basal ganglia arteriovenous malformations: redefining "Inoperable". Neurosurgery 2008;63 Suppl (1):63-69.

10. Schmidt K, Coimbra C. Endoscopic treatment of thalamic neuroepithelial cysts. Report of three cases. J Neurosurg. 2005;103:342-6.

11. Perlmutter $D$, Rhoton AL Jr. Microsurgical anatomy of the distal anterior cerebral artery. J Neurosurg. 1978;49(2):204-28.

12. Moshel YA, Elliott RE, Monoky DJ, Wisoff JH. Role of diffusion tensor imaging in resection of thalamic juvenile pilocytic astrocytom. J Neurosurg: Pediatrics. 2009;4(6):495-505

13. Rollins NK. Clinical applications of diffusion tensor imaging and tractography in children. Pediatr Radiol. 2007;37:769-80.

14. Bernstein M, Hoffman HJ, Halliday WC, Hendrick EB, Humphreys RP. Thalamic tumors in children. Long-term follow-up and treatment guidelines. J Neurosurg. 1984;61(4):649-56.

15. Franzini A, Leocata F, Cajola L, Servello D, Allegranza A, Broggi G. Low-grade glial tumors in basal ganglia and thalamus: natural history and biological reappraisal. Neurosurg. 1994;35(5):817-20.

16. Ahn ES, Goumnerova L. Endoscopic biopsy of brain tumors in children: diagnostic success and utility in quiding treatment strategies. J Neurosurg: Ped. 2010;5(3):255-62.

17. Moshel YA, Link MJ, Kelly PJ. Stereotactic volumetric resection of thalamic pilocytic astrocytomas. Neurosurg. 2007;61:66-75.

18. Yasargil MG, Abdulrauf SI. Surgery of intraventricular tumors. Neurosurg 2008; 62:(SHC Suppl 3):1029-1041.

19. Kawashima M, Rhoton AL Jr, Matsushima T. Comparison of posterior approaches to the posterior incisural space: microsurgical anatomy and proposal of a new method, the Occipital bi-transtentorial/falcine approach. Neurosurg. 2002;51:1208-21.

20. Tirakotai W, Hellwig D, Bertalanffy H, Riegel T. The role of neuroendoscopy in the management of solid or solid-cystic intra- and periventricular tumours. Childs Nerv Syst. 2007;23(6):653-8.

21. Air EL, Leach JL, Warnick RE, McPherson C. Stereotactic Radiosurgery. Comparing the risks of frameless stereotactic biopsy in eloquent and non eloquent regions of the brain: a retrospective review of 284 cases. Clinical article. J Neurosurg. 2009;111(4):820-4.

22. Zhang P, Wang X, Ji N, Xie J, Han J, Ren X, et al. Clinical, radiological, and pathological features of 33 adult unilateral thalamic gliomas. World I Surg Oncol. 2016;14:78

23. Bruce JN. Pineal region masses: clinical features \& management. In: Schmidek HH, Roberts DW, editors. Schmidek \& Sweet Operative Neurosurgical Techniques. Indications, Methods, and Results. 5th ed. Philadelphia: Elsevier; 2006. p. 786-97.

24. Eisenstat DD, Pollack IF, Demers A, Sapp MV, Lambert P, Weisfeld-Adams JD, Burger PC, Gilles F, Davis RL, Packer R, Boyett JM, Finlay JL. Impact of tumor location and pathological discordance on survival of children with midline high-grade gliomas treated on Children's Cancer Group high-grade glioma study CCG-945. J Neuro-Oncol. 2015;121:573-81.

25. Sai Kiran NA, Thakar S, Dadlani R, Mohan D, Furtado SV, Ghosal N, Aryan S, Hegde AS. Surgical management of thalamic gliomas: case selection, technical considerations, and review of literature. Neurosurg Rev. 2013;36: 383-93.

\section{Publisher's Note}

Springer Nature remains neutral with regard to jurisdictional claims in published maps and institutional affiliations. 